\title{
Dietary lipids reduce the expression of carotenoid-based coloration in Lacerta vivipara
}

\author{
Luis M. San-Jose ${ }^{*, 1,2}$, Fernando Granado-Lorencio ${ }^{3}$ and Patrick S. Fitze \\ ${ }^{1}$ Department of Biodiversity and Evolutionary Biology, Museo Nacional de Ciencias Naturales (MNCN-CSIC), 28006 \\ Madrid, Spain; ${ }^{2}$ Instituto Pirenaico de Ecología (IPE-CSIC), 22700 Jaca, Spain; ${ }^{3}$ Servicio de Bioquímica Clinica, Unidad \\ de Vitaminas, 28222 Majadahonda, Spain; ${ }^{4}$ Fundación Araid, Edificio Pignatelli, Paseo Maria Agustin 36, 50004 \\ Zaragoza, Spain; and ${ }^{5}$ Department of Ecology and Evolution (DEE), University of Lausanne, 1015 Lausanne, \\ Switzerland
}

\section{Summary}

1. The importance of dietary lipids for carotenoid-based ornaments has rarely been investigated, although theory predicts that dietary lipids may control the development of these widespread animal signals. Dietary lipids have been suggested to enhance the expression of male carotenoidbased ornaments because they provide carotenoids with a hydrophobic domain that facilitates their absorption and transport. Dietary lipids may also enhance the uptake of tocopherols (vitamin E), which share common absorption and transport routes with carotenoids. Here, we test whether dietary lipids enhance carotenoid availability and male carotenoid-based colorations. We also explore the effects of dietary lipids on plasma tocopherol concentration, which allow disentangling between different pathways that may explain how dietary lipids affect ornamental expression.

2. Following a two-factorial design, we manipulated dietary access of naturally occurring fatty acids (oleic acid) and carotenoids (lutein and zeaxanthin) and measured its effects on the circulating concentrations of carotenoids (lutein and zeaxanthin) and vitamin $E(\alpha-$ and $\gamma-(\beta-)$ tocopherols) and on the ventral, carotenoid-based coloration of male common lizards (Lacerta vivipara).

3. Lutein but not zeaxanthin plasma concentrations increased with carotenoid supplementation, which, however, did not affect coloration. Lipid intake negatively affected circulating concentrations of lutein and $\gamma-(\beta-)$ tocopherol and led to significantly less orange colorations. The path analysis suggests that a relationship between the observed colour change and the change in plasma concentrations of $\gamma-(\beta-)$ tocopherol may exist.

4. Our study shows for the first time that dietary lipids do not enhance but reduce the intensity of male carotenoid-based ornaments. Although dietary lipids affected plasma carotenoid concentration, its negative effect on coloration appeared to be linked to lower vitamin E plasma concentrations. These findings suggest that a conflict between dietary lipids and carotenoid and tocopherol uptake may arise if these nutrients are independently obtained from natural diets and that such conflict may reinforce signal honesty in carotenoid-based ornaments. They also suggest that, at least in the common lizard, sexual selection with respect to carotenoid-based coloration may select for males with low antioxidant capacity and thus for males of superior health.

Key-words: carotenoid-based ornaments, fat intake, protection hypothesis, signal honesty, sparing hypothesis, tocopherol, visual signals, vitamin E

\section{Introduction}

Carotenoid-based ornaments displayed by birds, fish and lizards can function as honest signals of individual quality

*Correspondence author. E-mail: Imsanjose@mncn.csic.es
(Olson \& Owens 1998; Svensson \& Wong 2011). Several (non-exclusive) mechanisms ensuring honesty have been proposed based on the assumption that carotenoid-based ornaments are costly to produce or display (Svensson \& Wong 2011). Animals cannot synthesize carotenoids de novo and depend on dietary carotenoid intake (Goodwin 


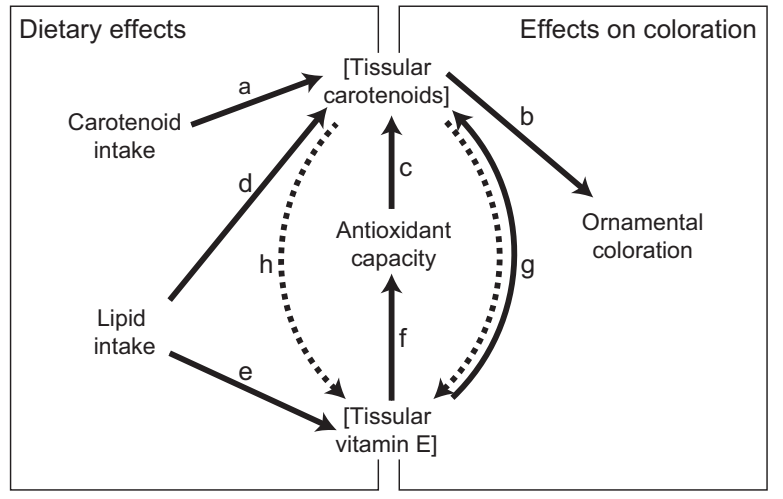

Fig. 1. Hypothesized pathways explaining how dietary lipids and carotenoids may affect tissular carotenoid and vitamin E concentrations and carotenoid-based ornaments (the figure only includes pathways important for this study). Dietary effects on tissular concentration of carotenoids and vitamin $\mathrm{E}$ are shown in the left panel, effects of tissular carotenoid and vitamin $\mathrm{E}$ use are shown in the middle and effects on coloration are shown in the right panel. Continuous lines indicate positive and dotted lines negative relationships. Carotenoid intake enhances tissular carotenoid concentrations (path a). Lipid intake determines carotenoid and tocopherol absorption and transport and thereby tissular carotenoid or tocopherol concentration (paths d and e). Antioxidant capacity may affect tissular carotenoids (path c) and vitamin E (path h) and both the sparing effect (path i) and the protection hypothesis (path d) may explain the link between tissular tocopherols and carotenoids. All pathways may finally affect ornamental carotenoid-based coloration through their effects on tissular carotenoid concentration (path b).

1986). The amount of carotenoids obtained with the diet may thus limit tissular carotenoid concentration (Fig. 1, path a) and thereby the development of intense carotenoidbased ornaments (Fig. 1, path b; Hill 1990; Tschirren, Fitze \& Richner 2003). Once ingested, carotenoids can be used for ornamentation but also for other functions. Carotenoids may serve as antioxidants (Bendich 1989; Krinsky 1989; Chew \& Park 2004) and, hence, individual requirements for antioxidants may determine tissular carotenoid concentration (Fig. 1, path c) and the availability of carotenoids for ornamentation (Fig. 1, path b; Lozano 1994; von Schantz et al. 1999; Pérez, Lores \& Velando 2008). In contrast to this hypothesis, it has been suggested that carotenoids are signalling the excellence of antioxidant resources rather than functioning as antioxidants (Hartley \& Kennedy 2004). Hartley \& Kennedy (2004) proposed that carotenoids may be vulnerable to oxidation and argued that 'given that oxidation of carotenoids alters or destroys their colour (i.e. bleaches them), preservation of their colour intensity would indicate the possession of efficient means for their protection'. In this scenario, colour intensity would be an indicator of antioxidant capacity but carotenoids themselves would not be responsible for antioxidation (Hartley \& Kennedy 2004).

According to above-stated hypotheses, carotenoid-based ornaments may depend on access to carotenoids as well as antioxidants, and therefore on factors modulating absorption, transport and metabolism of carotenoids and antioxidants
(Hill 2000; McGraw \& Parker 2006; Fitze et al. 2007). Nutritional and biomedical literature indicates that dietary lipid intake is essential for an efficient assimilation of dietary carotenoids (Erdman, Bierer \& Gugger 1993; Parker 1996; van het Hof et al. 2000; Yonekura \& Nagao 2007). Lipids provide carotenoids with a hydrophobic domain that favours their emulsion from the intestinal lumen, their inclusion into mixed micelles and their posterior absorption in the duodenal cells. After absorption, dietary lipids enhance carotenoid transport by stimulating the formation of carotenoid carriers; chylomicrons and lipoproteins (Borel et al. 1998; Silva et al. 2003). Consequently, increased lipid intake may lead to higher tissular carotenoid availability, as demonstrated in humans and laboratory mammal species (Fig. 1, path d; Dimitrov et al. 1988; Brown et al. 2004; Unlu et al. 2005). The importance of dietary lipids has been rarely investigated in species with carotenoid-based ornaments, which may importantly differ from mammals in carotenoid dynamics (Hill 1999). The enhancing effect of dietary lipids on carotenoid assimilation and transport may translate into improved ornamental expression. Moreover, its effect may be higher at low than at high dietary carotenoid concentrations (RibayaMercado 2002), suggesting that the scarcer carotenoids are in the diet the stronger dietary lipids may affect carotenoidbased ornaments. Thus, between-individual variation in dietary lipid access may help to understand how differences in carotenoid availability and carotenoid-based ornaments arise and how these differences become related to differences in individuals' quality.

Because tocopherols (i.e. vitamin E) share absorption and transport routes with carotenoids, dietary lipids may also increase tocopherol uptake (Fig. 1, path e; Rock, Jacob \& Bowen 1996). Tocopherols are potent lipid-soluble antioxidants of dietary origin that may preferentially bolster antioxidant defences (Rock, Jacob \& Bowen 1996). In some species, enhanced tocopherol levels may therefore lead to the sparing of carotenoids, which can then be used for pigmentation (Fig. 1, path f-c-b; Pérez-Rodríguez 2009). Alternatively, enhanced tocopherol levels may increase the protection of carotenoids from oxidation, and thereby affect carotenoidbased ornaments (Fig. 1, path g-b; Hartley \& Kennedy 2004).

On the other hand, if dietary lipids lead to an increase in carotenoid concentration, they may also indirectly decrease tissular tocopherol concentrations. Thus, if carotenoids require antioxidant protection, enhanced carotenoid levels may increase the consumption of tocopherols owing to the toxic workings of carotenoid oxidation (Fig 1, path d-g; Palozza 1998). Alternatively, if carotenoids function as antioxidants, enhanced carotenoid concentrations owing to increased lipid uptake may spare other antioxidants from antioxidant functions, which is known as homoeostatic sparing (Svensson \& Wong 2011). According to the sparing hypothesis, non-carotenoid antioxidants, including tocopherol, are preferentially used if carotenoids are scarce, and down-regulated if carotenoids are plentiful, which is suggested to explain the negative correlations that have been 
previously observed between carotenoid intake and the tocopherol concentration of some tissues (Fig. 1, path d-h; Surai 2002).

To our knowledge, only one study has considered the role of dietary lipids on the expression of carotenoid-based ornaments. McGraw \& Parker (2006) showed that dietary cholesterol supplementation enhances blood carotenoid content and carotenoid-based coloration of Taenopygia guttata (zebra finch). Because $T$. guttata does not naturally ingest cholesterol (McGraw \& Parker 2006), these findings need to be confirmed with naturally ingested lipids. Further, no evidence exists for the existence of similar effects in other species and thus the generality of these findings remains unknown.

Here, we investigate the effects of dietary lipids on carotenoid-based ornaments using male common lizards, Lacerta vivipara Jacquin, 1787, as a study organism. To investigate by which mechanisms dietary lipids may affect coloration, we simultaneously supplemented lizards with lipids and carotenoids using a $2 \times 3$ factorial design and measured plasma carotenoid and tocopherol concentrations. Male common lizards exhibit a ventral, yellow-orange coloration that is based on carotenoids (Fitze et al. 2009). We predicted that dietary lipid supplementation positively affects plasma carotenoid concentrations (Fig. 1, path d). We also expect that differences between lizards supplemented with dietary lipids and control lizards will increase with decreasing amounts of dietary carotenoids, i.e. when carotenoids are scarcer. We further predict that enhanced carotenoid concentrations positively affect ornamentation, through increased carotenoid incorporation into ornamental coloration (Fig. 1, path b). We also predicted that dietary lipids may directly increase plasma tocopherol concentrations (Fig. 1, path e) or indirectly (i.e. through enhancing carotenoid uptake) decrease them as predicted by the protection hypothesis (Fig. 1, path d-g) or the sparing effect (Fig. 1, path d-h). If enhanced carotenoid uptake mediates indirect effects of dietary lipids in plasma tocopherol concentrations, carotenoid supplementation should also negatively affect plasma tocopherol concentration (Fig. 1, path $\mathrm{a}-\mathrm{h}$ or $\mathrm{a}-\mathrm{g}$ ).

\section{Materials and methods}

\section{SPECIES DESCRIPTION, STUDY SITE AND BREEDING CONDITIONS}

The common lizard is a small ground-dwelling lizard that inhabits humid habitats across Europe and Asia (Sindaco \& Jeremcenko 2008). It is an insectivore species that mainly preys on spiders and Homoptera but also on larger preys like earthworms (Avery 1966, 1971; Heulin 1986). In the first year of life, males develop a yellow-orange carotenoid-based coloration that plays a role in sex recognition and female mate choice (Bauwens et al. 1987; Fitze et al. 2009; Cote et al. 2010). Male coloration is maintained throughout the year and does not fade after the breeding season. The presence of other yellow-orange pigments, like pteridines, has been discarded (Fitze et al. 2009).

On 2 August 2007, 42 adult males were captured in a natural population located at Puerto de Ibañeta, Spanish Pyrenees $\left(43^{\circ} 1^{\prime} \mathrm{N}\right.$, $\left.1^{\circ} 19^{\prime} \mathrm{W}\right)$. The experiment was conducted from August to the end of
September because food intake during these months (i.e. before hibernation) determines common lizard's condition in spring and, hence, in the mating period (Avery 1970; Roig, Carretero \& Llorente 2000; Bleu et al. 2011). After capture, animals were moved to the laboratory at the Instituto Pirenaico de Ecología-CSIC (Jaca, Spain) and snout to vent length (SVL, to the nearest $1 \mathrm{~mm}$ ) and body mass (to the nearest $1 \mathrm{mg}$ ) were measured. Lizards were individually housed in terraria $(25 \times 15 \times 15 \mathrm{~cm})$ containing two different shelters and peat soil as substrate. A $40 \mathrm{~W}$ bulb provided light and heat for $8 \mathrm{~h}$ a day and a UV light (5\% UV-B and 30\% UV-A; Sylvania Reptistar ${ }^{\circledR}$, London, UK) illuminated the terraria during $2 \mathrm{~h}$ per day. Lizards were left to acclimate to laboratory conditions for 10 days. During this period, water was provided ad libitum and lizards were fed with a Galleria mellonella (wax worm) larva every 4 days.

\section{DIET MANIPULATION}

During 31 days, dietary lipids and carotenoids were manipulated following a $2 \times 3$ factorial design. Half of the lizards were randomly assigned to a fat-supplemented group $(N=21)$ and the other half to an unsupplemented group $(N=21)$. Within fat-supplemented and unsupplemented groups, lizards were randomly assigned to three different carotenoid supplementation groups $(N=7$ per carotenoid and fat supplementation group). Starting on day 1 , lizards were fed every 2 days with a $G$. mellonella larvae injected with the corresponding fat and carotenoid supplementation. Fat and carotenoids were injected into G. mellonella larvae to assure that carotenoids could dissolve in dietary lipids. Body mass was periodically measured (days 1 , 9,22 and 31) and the number of larvae eaten was counted to investigate treatment effects on appetite.

Lizards were supplemented with oleic acid, a monounsaturated fatty acid that predominates in insectivore diets (Barlow 1963; Fast 1966; Schneider \& Dorn 1994; Buckner, Kemp \& Bosch 2004; Speake, Herbert \& Thompson 2004; Bashan 2005; Michaud \& Denlinger 2006; Khani et al. 2007) and reptile reserve tissues (Ballinger et al. 1992; Cartland-Shaw et al. 1998; Thompson et al. 2001). Fat-supplemented lizards were fed with a G. mellonella larvae injected with $0 \cdot 12 \mathrm{~mL}$ pure olive oil ( $72 \%$ oleic acid), while unsupplemented lizards were fed with larvae injected with $0 \cdot 12 \mathrm{~mL}$ of distilled water. Thus, lizards in the fat-supplemented group received approximately three times more oleic acid and 1.5 times more fat than lizards in the unsupplemented group (Finke 2002).

Lizards were supplemented with lutein and zeaxanthin, which account for $99 \cdot 1 \%$ of the plasma carotenoids present in common lizards of Pyrenean populations (San-Jose, Granado-Lorencio \& Fitze, 2012). Lizards supplemented with a high dose of carotenoids were fed with $G$. mellonella larvae injected with $30 \mu \mathrm{L}$ of a solution containing $2 \mathrm{mg}$ lutein and zeaxanthin beadlets (lutein: $5 \cdot 58 \%$ and zeaxanthin: $0 \cdot 44 \%$; Hoffmann-La Roche Ltd., Basel, Switzerland) in $1 \mathrm{~mL}$ distilled water. Lizards supplemented with an intermediate dose of carotenoids were fed with $G$. mellonella larvae injected with $30 \mu \mathrm{L}$ of a solution containing $1 \mathrm{mg}$ lutein and zeaxanthin beadlets and $1 \mathrm{mg}$ control beadlets diluted in $1 \mathrm{~mL}$ distilled water. Finally, lizards in a control dose group were fed with G. mellonella larvae injected with $30 \mu \mathrm{L}$ of a solution of $2 \mathrm{mg}$ control beadlets in $1 \mathrm{~mL}$ distilled water (Fitze et al. 2009).

\section{HPLC ANALYSES}

On day 1, 21 and 36, blood samples were taken from the retro-orbital sinus using heparinized microcapillaries. Blood was thereafter 
centrifuged ( $5 \mathrm{~min}$ at $8900 \mathrm{~g}$ ) and the obtained plasma was stored at $-80{ }^{\circ} \mathrm{C}$. HPLC analyses were run on a subset of 21 randomly selected males. There were no statistical differences in SVL, body mass and body condition between the subset and the rest of the animals (all $P>0.41)$.

Plasma concentrations of lutein, zeaxanthin, and $\alpha$ - and $\gamma-(\beta-)$ tocopherol were analysed using HPLC (Olmedilla et al. 1997). Plasma samples were mixed with $0 \cdot 1 \mathrm{~mL}$ distilled water and $0 \cdot 2 \mathrm{~mL}$ ethanol (EtOH) and extracted twice with $0.5 \mathrm{~mL}$ methylene chloride : hexane (1:5). Organic phases were pooled, evaporated to dryness and reconstituted in tetrahydrofuran (THF) : EtOH to be injected onto the HPLC column. The chromatographic system consisted of a Spheri-5-ODS column (Applied Biosystems, San Jose, CA, USA) with gradient elution of acetonitrile : methanol (85:15; $5 \mathrm{~min})$ to acetonitrile : methylene chloride : methanol (70:20:10; $20 \mathrm{~min})$. Ammonium acetate $(25 \mathrm{~mm})$ was added to the methanol. Carotenoid detection was carried out with a photodiode array (model 2996; Waters Associates, Milford, MA, USA) set at $450 \mathrm{~nm}$. Tocopherols were detected using the same photodiode set at $295 \mathrm{~nm}$ and using a fluorescence detector (excitation: $290 \mathrm{~nm}$, emission: $330 \mathrm{~nm}$ ). Identification of the compounds was carried out by comparing retention times with those of authentic standards and online UV-visible spectra. The accuracy of the analytical method was periodically verified through our participation in the Fat-Soluble Quality Assurance Program (National Institute of Standards and Technology, Gaithersburg, MD, USA).

\section{COLOUR MEASUREMENTS}

Coloration was measured using a tristimulus scoring system based on measures of hue, chroma and brightness (Endler 1990). Coloration was measured on day 1, 10, 22 and 31 using an USB4000 spectrometer (Ocean Optics Inc., Dunedin, FL, USA) attached to a deuterium tungsten halogen light source (DT-MINI-2-GS; Ocean Optics Inc.) by an optic fibre probe (QR400-7-UV/VIS-BX; Ocean Optics Inc.). Spectral reflectance of the throat scales, anal plate and inner ventral scales was measured in relation to a diffuse white standard (WS-1; Ocean Optics Inc.) using an angle of $45^{\circ}$. All measurements showed high repeatability (repeatability based on two repeated measurements: $F_{10,11} \geq 5 \cdot 23, P \leq 0 \cdot 01, r \geq 0 \cdot 68$; Lessells \& Boag 1987).

\section{STATISTICS}

At the beginning of the experiment, there were no significant differences between treatment groups in SVL, body mass and body condition (all $P>0 \cdot 57$ ). Two lizards died during the experiment and, thus, were excluded from all analyses. Treatment effects on appetite were analysed using ANOVAS with fat and carotenoid treatment and their interaction as factors. Treatment effects on repeated measures of body mass, plasma concentrations of lutein, zeaxanthin, $\alpha$ - and $\gamma-(\beta-)$ tocopherol and colour variables were analysed using the MIXED procedure implemented in SAS 9 system (SAS Institute Inc., Cary, NC, USA; Littell, Henry \& Ammerman 1998). Full models included fat and carotenoid treatment and their interaction as fixed factors and individual as random effect. Time effects were investigated by fitting linear and quadratic trends and their interaction with fat and carotenoid treatment. The covariance structure of each model was selected following the Akaike criterion (Wolfinger 1996; Littell, Henry \& Ammerman 1998). Model simplification was carried out using backward elimination of non-significant terms. To elucidate by which mechanisms fat and carotenoid supplementation affected coloration, we ran path analyses using multivariate regression models based on standardized variables (Fitze \& Le Galliard 2008). Path analysis was used to distinguish between direct and indirect treatment effects on coloration, e.g. treatment effects on coloration owing to treatment effects on tissular carotenoid and/or tocopherol concentrations. Moreover, they unravel the relative importance of the applied treatments and of the changes (final - initial measures) in tocopherol and carotenoid concentrations that result in coloration changes.

The significance level was set at $P=0.05$ (two-tailed) and it was adjusted following Hochberg (1988) procedures to control familywise Type I error rate when using multiple contrasts. If necessary, variables were transformed to meet model assumptions. Some models did not meet the homoscedasticity assumption and weighted leastsquare regressions were fitted instead (Neter et al. 1996). Cohen's $d$ estimates of effect sizes and $95 \%$ confidence intervals were obtained following calculations for mixed models described in Nakagawa \& Cuthill (2007).

\section{Results}

\section{EFFECTS ON APPETITE AND BODY MASS}

Over the course of the experiment, lizards ate a total of $12 \pm 0 \cdot 5$ (mean $\pm \mathrm{SE}$ ) larvae. Appetite was not significantly affected by fat treatment $\left(F_{1,36}=0 \cdot 21, P=0 \cdot 65\right)$, carotenoid treatment $\left(F_{2,36}=1 \cdot 24, P=0 \cdot 30\right)$ and their interaction $\left(F_{2,34}=1 \cdot 10, P=0 \cdot 35\right)$. During the first weeks of the experiment, lizards showed a significant decrease in body mass that was followed by a slight increase at the end of the experiment (time: estimate $\pm \mathrm{SE}=-0.177 \pm 0.062 \mathrm{~g}, F_{1,110}=7.26$, $P=0.008 ; \quad$ time $^{2}$ : estimate $\pm \mathrm{SE}=0.039 \pm 0.011 \mathrm{~g}$, $F_{1,110}=43.33, P<0 \cdot 001$ ). Body mass was not significantly affected by fat treatment (fat treatment $\times$ time: $F_{1,110}=$ $0.78, \quad P=0.38 ; \quad$ fat treatment $\times$ time $^{2}: \quad F_{1,110}=2.90$, $P=0.09$ ), carotenoid treatment (carotenoid treatment $\times$ time: $F_{2,110}=1 \cdot 51, P=0 \cdot 22$; carotenoid treatment $\times$ time $^{2}$ : $F_{2,110}=0.18, \quad P=0.83$ ) or the three-way interactions between fat treatment, carotenoid treatment, and time or time $^{2}($ all $P>0 \cdot 10)$.

\section{EFFECTS ON PLASMA CAROTENOIDS AND TOCOPHE- ROLS}

Over the course of the experiment, fat and carotenoid treatment significantly affected plasma lutein concentration in a quadratic manner (Table 1; Fig. 2) and the interaction between the two treatments was not significant (all $P>0.75)$. Fat-supplemented lizards showed a significant decrease in plasma lutein concentration over the course of the experiment $\left(F_{1,19}=9 \cdot 52, P=0 \cdot 006\right.$; Fig. 2a). In contrast, plasma lutein concentrations of unsupplemented lizards increased until day 21 , when they reached a maximum and started to decrease (time: $F_{1,20}=10 \cdot 74, P=0 \cdot 004$; time $^{2}$ : $F_{1,20}=9 \cdot 71, P=0 \cdot 006$ ). Plasma lutein concentrations of lizards supplemented with high and intermediate doses of carotenoids increased until day 21 and then decreased (high dose; time: $F_{1,10}=13 \cdot 10, P=0 \cdot 005$; time ${ }^{2}: F_{1,10}=12 \cdot 87$, $P=0 \cdot 005, \quad$ intermediate dose; time: $F_{1,14}=6 \cdot 11$, 
Table 1. Treatment effects on plasma concentration of lutein and zeaxanthin

\begin{tabular}{|c|c|c|c|c|c|c|c|c|}
\hline \multirow[b]{2}{*}{ Parameter } & \multicolumn{4}{|l|}{ Lutein } & \multicolumn{4}{|l|}{ Zeaxanthin } \\
\hline & Test statistic & $P$ & $\begin{array}{l}\text { Effect } \\
\text { size }(d)\end{array}$ & $95 \% \mathrm{CI}$ & Test statistic & $P$ & $\begin{array}{l}\text { Effect } \\
\text { size }(d)\end{array}$ & $95 \% \mathrm{CI}$ \\
\hline Time & $F_{1,34}=6.86$ & $0 \cdot 013$ & $0 \cdot 56$ & $0 \cdot 11-1 \cdot 07$ & $F_{1,40}=4.62$ & 0.037 & $0 \cdot 41$ & $0 \cdot 02-0 \cdot 84$ \\
\hline Time $^{2}$ & $F_{1,34}=8.55$ & 0.006 & 0.62 & $0 \cdot 17-1 \cdot 16$ & $F_{1,40}=2 \cdot 95$ & $0 \cdot 093$ & & \\
\hline Fat treatment $\times$ time & $F_{1,34}=9 \cdot 71$ & 0.004 & 0.65 & $0 \cdot 21-1 \cdot 08$ & $F_{1,37}=1 \cdot 67$ & $0 \cdot 204$ & & \\
\hline Fat treatment $\times$ time $^{2}$ & $F_{1,34}=6 \cdot 15$ & 0.018 & $0 \cdot 51$ & $0.09-0.94$ & $F_{1,34}=0 \cdot 40$ & 0.532 & & \\
\hline Carotenoid treatment $\times$ time & $F_{2,34}=17 \cdot 33$ & $<0.001$ & $\begin{array}{l}1 \cdot 67 \dagger \\
1 \cdot 11 \ddagger\end{array}$ & $\begin{array}{l}0.94-2 \cdot 38 \\
0.51-1 \cdot 70\end{array}$ & $F_{2,37}=1 \cdot 87$ & $0 \cdot 168$ & & \\
\hline Carotenoid treatment $\times$ time $^{2}$ & $F_{2,34}=15 \cdot 02$ & $<0.001$ & $\begin{array}{l}1 \cdot 54 \dagger \\
1 \cdot 02 \ddagger\end{array}$ & $\begin{array}{l}0 \cdot 83-2 \cdot 24 \\
0 \cdot 43-1 \cdot 60\end{array}$ & $F_{2,35}=0.94$ & $0 \cdot 402$ & & \\
\hline
\end{tabular}

Test statistics of mixed models with linear and quadratic time effects are given. Bold values are statistically significant. Effect size $(d)$ and $95 \%$ confidence intervals are given for statistically significant parameters.

$\dagger$ Estimate for high carotenoid dose group vs. control dose group.

\$Estimate for intermediate carotenoid dose group vs. control dose group.
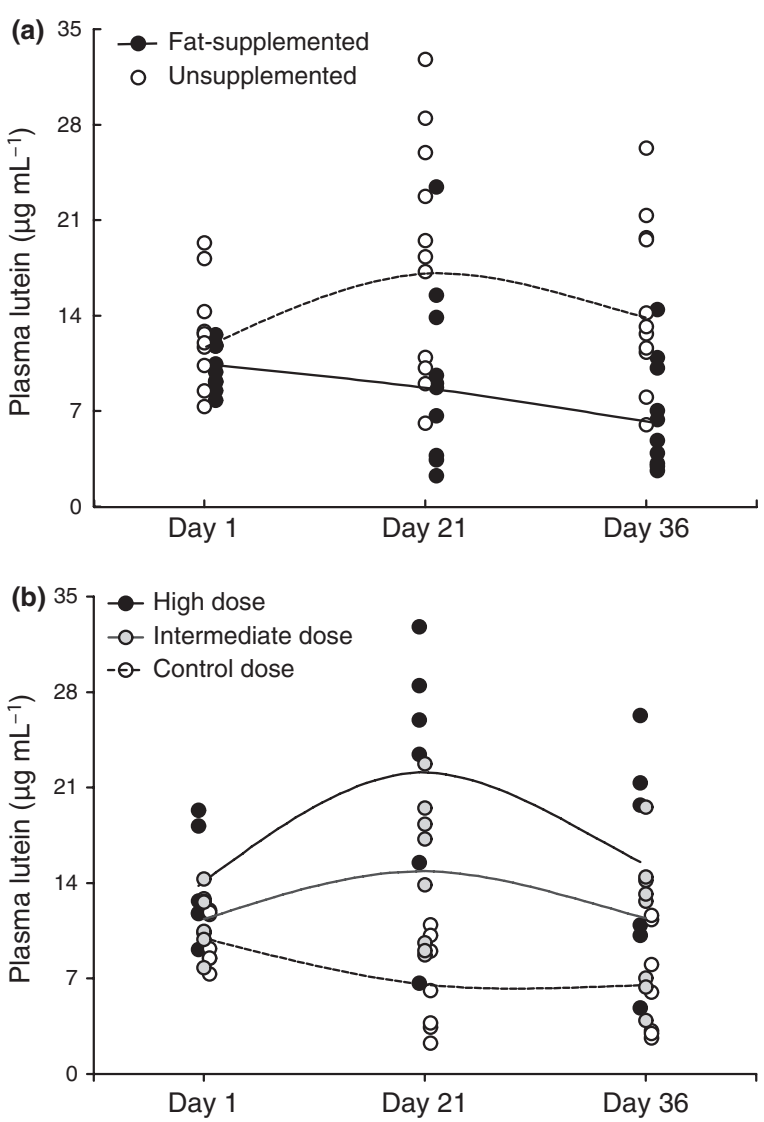

Fig. 2. Effects of fat (a) and carotenoid (b) treatment on plasma lutein concentration. Points represent observed data and lines represent model predictions for each treatment level.

$P=0.027$; time ${ }^{2}: F_{1,14}=6 \cdot 45, P=0 \cdot 023$; Fig. 2b). In the control dose group, lutein concentration decreased from days 1 to 21 and remained low until day 36 (time: $F_{1,13}=6 \cdot 26$, $P=0 \cdot 026$ ). Individual contrasts showed that the changes observed in the high and intermediate dose groups were significantly different from those observed in the control dose

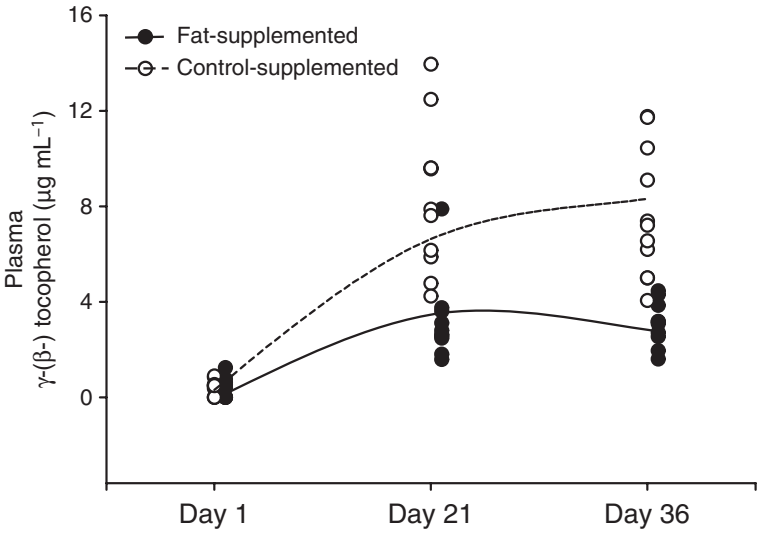

Fig. 3. Effects of fat treatment on plasma $\gamma-(\beta-)$ tocopherol concentration. Points represent observed data and lines represent model predictions for each treatment level.

group (high dose vs. control dose; time: $F_{1,34}=29 \cdot 38$, $P<0.0001 ;$ time $^{2}: F_{1,34}=25.20, P<0.0001$, intermediate dose vs. control dose; time: $F_{1,34}=16 \cdot 81, P<0.001$; time $^{2}$ : $\left.F_{1,34}=14.14, P<0.001\right)$, but not between the carotenoidsupplemented groups (high dose vs. intermediate dose; time: $F_{1,34}=2 \cdot 72, P=0 \cdot 11$; time $\left.{ }^{2}: F_{1,34}=2 \cdot 43, P=0 \cdot 13\right)$. Zeaxanthin concentration in plasma significantly decreased over the course of the experiment and it was not affected by any of the treatments (Table 1) or their interaction (all $P>0 \cdot 34$ ).

Fat treatment significantly affected plasma $\gamma-(\beta-)$ tocopherol concentration (time: $F_{1,39}=9 \cdot 43, P=0.004$, effect size $d=0 \cdot 24, \quad 95 \% \quad$ CI $=0 \cdot 07-0 \cdot 40 ; \quad$ time $^{2}: \quad F_{1,39}=5 \cdot 30$, $P=0.027$, effect size $d=0 \cdot 18,95 \%$ CI $=0.02-0.33$; fat treatment $\times$ time: $\quad F_{1,39}=13.60, \quad P<0.001$, effect size $d=0.28, \quad 95 \% \quad$ CI $=0 \cdot 12-0 \cdot 45$; Fig. 3$)$. Plasma $\gamma-(\beta-)$ tocopherol concentration significantly increased in unsupplemented lizards, while in fat-supplemented lizards it increased less until day 21 and slightly decreased thereafter. Carotenoid treatment did not significantly affected $\gamma-(\beta-)$ tocopherol concentration (carotenoid treatment $\times$ time: $F_{2,36}=0.58$, 
$P=0.57)$ and the interaction between fat and carotenoid treatment was not significant (all $P>0 \cdot 43$ ). $\alpha$-Tocopherol concentration decreased during the experiment (time esti-

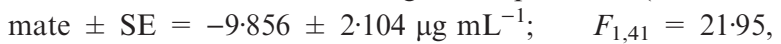
$P<0.001)$ and was not significantly affected by fat treatment (fat treatment $\times$ time: $F_{1,35}=0.02, P=0 \cdot 89$ ), carotenoid treatment (carotenoid treatment $\times$ time: $F_{2,38}=0.55$, $P=0 \cdot 58$ ) or their interaction (all $P>0 \cdot 27$ ).

\section{EFFECTS ON COLORATION}

Fat treatment significantly affected anal plate and throat scale hue (Table 2). Over the course of the experiment, hue of both anal plate and throat scale decreased more (i.e. became more orange) in unsupplemented than in fat-supplemented lizards (Fig. 4). A similar but not significant tendency was also found for ventral scale hue (Table 2; Fig. 4). Carotenoid treatment and its interaction with fat treatment did not significantly affect coloration (all $P \geq 0.63$ ) and there were no significant treatment effects on chroma (all $P \geq 0 \cdot 13$ ) and brightness (all $P \geq 0.33)$ in any of the measured body parts.

Path analysis (Fig. 5; Table 3) revealed that fat treatment negatively affected the change in plasma lutein concentration, i.e. lutein concentration decreased in fat-supplemented lizards and increased in unsupplemented lizards (see also Fig. 2). Similarly, fat treatment negatively affected the change in blood $\gamma-(\beta-)$ tocopherol concentration, i.e. tocopherol concentration increased less in fat-supplemented lizards than in unsupplemented lizards (see also Fig. 3). Fat treatment did not significantly affect the change in zeaxanthin and $\alpha$-tocopherol concentrations (Table 3). Carotenoid treatment positively affected the change in plasma lutein concentration and negatively affected plasma zeaxanthin concentration (Fig. 5). Individual contrasts showed an increase in lutein concentration in the high dose group compared to lizards supplemented with intermediate (estimate $\pm \mathrm{SE}=3.98 \pm$ $\left.1.60 \mu \mathrm{g} \mathrm{mL}^{-1}, t_{16}=2.49, P=0.048\right)$ and control doses (estimate $\pm \mathrm{SE}=6.05 \pm 1.53 \mu \mathrm{g} \mathrm{mL}^{-1}, t_{16}=3.95, P=$ $0.003)$. Lutein change was not significantly different between lizards fed with intermediate and control doses $\left(t_{16}=1 \cdot 39\right.$, $P=0 \cdot 18)$. The high dose group showed a higher decrease in plasma zeaxanthin than lizards in the intermediated dose group (estimate $\pm \mathrm{SE}=-0 \cdot 76 \pm 0 \cdot 28 \mu \mathrm{g} \mathrm{mL}^{-1}, \quad t_{17}=$ 2.72, $P=0.044)$ and tended to show a higher decrease than lizards in the control dose group (estimate $\pm \mathrm{SE}=-0.65 \pm$ $\left.0.31 \mu \mathrm{g} \mathrm{mL}^{-1}, t_{17}=2.08, P=0.08\right)$. Carotenoid treatment did not significantly affected the change in plasma $\alpha$ - and $\gamma-(\beta-)$ tocopherol concentrations. The change in lutein concentration significantly explained changes in zeaxanthin concentrations and vice versa. Changes between tocopherols and between tocopherols and carotenoids were not significantly related.

The change in plasma lutein, $\alpha$-tocopherol and zeaxanthin concentrations did not explain the change in hue on any of the three body parts. The change in $\gamma-(\beta-)$ tocopherol was negatively related to the hue change on ventral and throat scales and a trend existed on the anal plate. The smaller

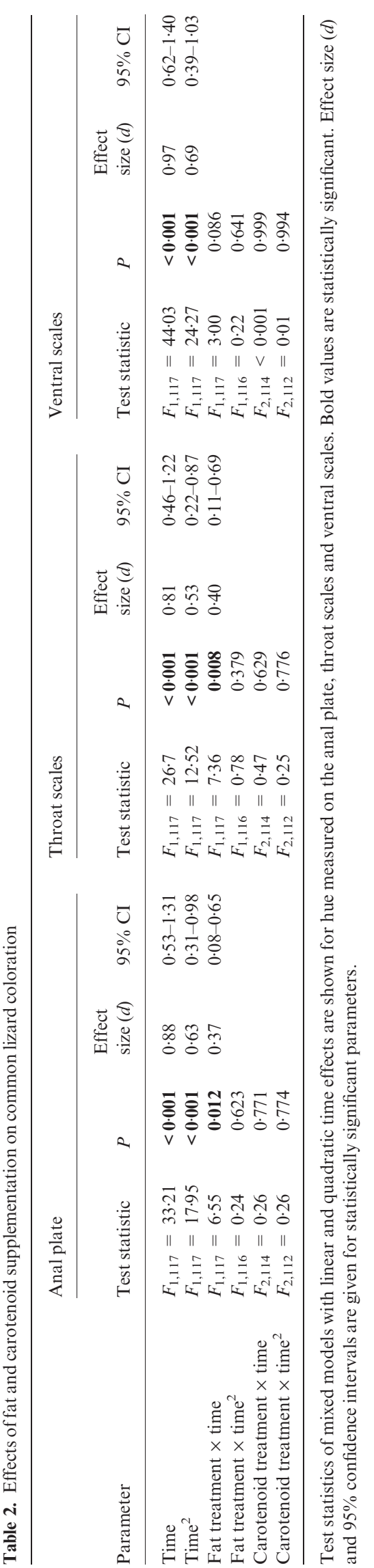



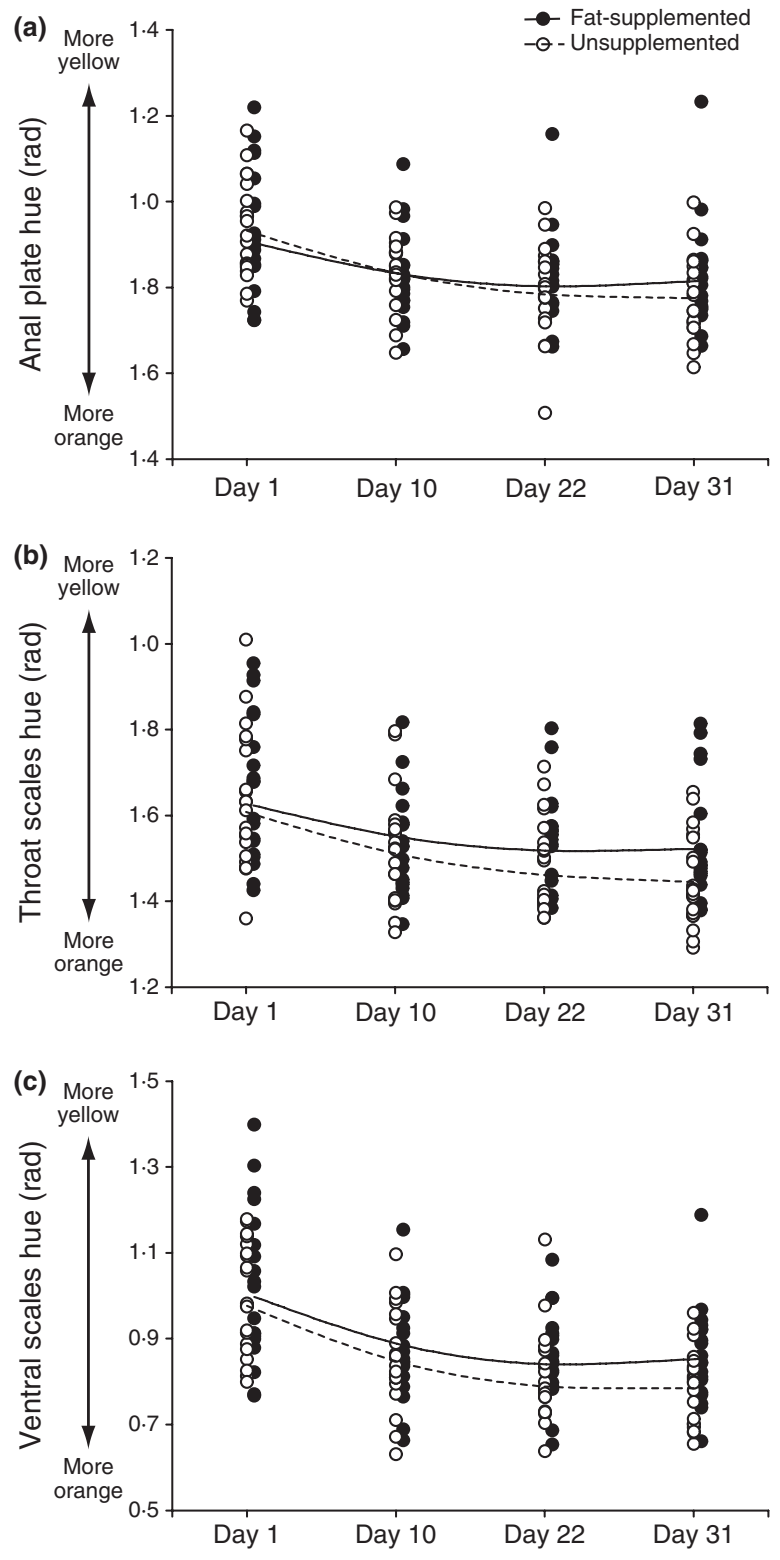

Fig. 4. Effects of fat treatment on anal plate (a), throat scale (b) and ventral scale (c) hue. Points represent observed data and lines represent group specific model predictions.

increase in $\gamma$ - $(\beta-)$ tocopherol concentration observed in the fat-supplemented group led to a smaller decrease in hue and thus to less orange coloration (Fig. 6). In contrast, individuals of the control-supplemented group showed a bigger increase in $\gamma-(\beta-)$ tocopherol concentration that led to a bigger decrease in hue and thus to more orange coloration (Fig. 6). No direct effect of the fat treatment existed on coloration (Table 3; Fig. 5).

\section{Discussion}

Here, we show that increased lipid intake reduced plasma concentration of lutein, which is the predominant carotenoid

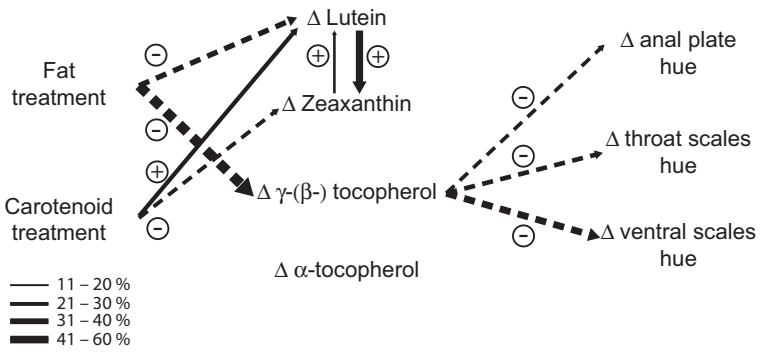

Fig. 5. Path diagram showing significant direct and indirect treatment effects on anal plate, throat scale and ventral scale hues. Arrows indicate significant and marginally significant effects. Negative and positive effects are indicated using dashed and continuous arrows, respectively. The direction of treatment effects is given for supplemented groups relative to the unsupplemented group (e.g. supplemented group $>$ unsupplemented group is referred to as a positive effect). For the zeaxanthin change, the direction of the carotenoid treatment is given for the high carotenoid dose group relative to the other groups. Arrow width is proportional to the explained variance (scale provided in the figure).

of common lizard tissues (San-Jose, Granado-Lorencio \& Fitze, 2012). The absence of a significant interaction between fat and carotenoid treatment suggests that lipid effects on plasma carotenoid content may be independent of carotenoid intake and, hence, that lipid effects may not depend on environmental scarcity of carotenoids or individual differences in obtaining carotenoids. Decreased plasma lutein concentration owing to lipid intake may have resulted from lipid effects on lutein absorption, transportation or excretion (Parker 1996). If dietary lipids impaired carotenoid absorption or increased carotenoid excretion, we would have expected no differences between fat treatment groups in the carotenoid control group, given that the carotenoid control group was provided with a neglectable quantity of carotenoids (0.53$0.86 \%$ of the carotenoid reserves of common lizards; SanJose, Granado-Lorencio \& Fitze, 2012). On the contrary, if lipids impaired post-absorption mechanisms (e.g. carotenoid transport), we expected a similar effect of fat treatment in all carotenoid treatment groups. The absence of a significant interaction between lipid and carotenoid treatment therefore suggests that dietary lipids may have affected lutein during post-absorption but not during absorption or excretion. Because lipids and carotenoids are transported by plasma lipoproteins, which are formed after absorption, increased competition between lipids and carotenoids for inclusion into lipoproteins may have compromised carotenoid transport capacity in fat-supplemented lizards (Parker 1996). Our findings are not in line with previous studies conducted on humans and laboratory mammal species, where dietary lipids did enhance carotenoid uptake (Yonekura \& Nagao 2007). In contrast to mammals, species displaying carotenoid-based ornaments usually present higher circulating carotenoid concentrations, which has been suggested to result from important differences in carotenoid dynamics and utilization (review in Hill 1999). Our findings may also reflect such differences, supporting that extrapolation from observations made 
Table 3. Results from path analysis discerning between direct treatment effects on changes in hue of the anal plate, throat scales, and ventral scales and indirect treatment effects mediated by changes in carotenoid and tocopherol concentrations

\begin{tabular}{|c|c|c|c|c|c|c|}
\hline \multirow[b]{3}{*}{ Dependent variables } & \multicolumn{6}{|c|}{ Independent variable } \\
\hline & \multicolumn{2}{|l|}{ Direct effects } & \multicolumn{4}{|l|}{ Indirect effects } \\
\hline & Fat treatment & $\begin{array}{l}\text { Carotenoid } \\
\text { treatment }\end{array}$ & $\Delta$ Lutein & $\Delta$ Zeaxanthin & $\Delta \gamma-(\beta-)$ Tocopherol & $\Delta \alpha$-Tocopherol \\
\hline$\Delta$ Lutein & $F_{1,16}=\mathbf{2 0 \cdot 7 8 ^ { * * * }}$ & $F_{2,16}=\mathbf{8} \cdot 36^{* *}$ & - & $F_{1,16}=\mathbf{9}^{2} \mathbf{5 8} * *$ & $F_{1,15}=1 \cdot 56$ & $F_{1,14}=1.06$ \\
\hline$\Delta$ Zeaxanthin & $F_{1,16}=2 \cdot 04$ & $F_{2,17}=\mathbf{3}^{2} \cdot \mathbf{3}^{*}$ & $F_{1,17}=14 \cdot 63^{* * *}$ & - & $F_{1,15}=1 \cdot 41$ & $F_{1,14}=0.06$ \\
\hline$\Delta \gamma-(\beta-)$ Tocopherol & $F_{1,19}=\mathbf{2 3 \cdot 5 6} * * *$ & $F_{2,17}=1 \cdot 19$ & $F_{1,16}=1 \cdot 81$ & $F_{1,15}=1 \cdot 41$ & - & $F_{1,14}=0.58$ \\
\hline$\Delta \alpha$-Tocopherol & $F_{1,16}=0 \cdot 62$ & $F_{2,18}=0.65$ & $F_{1,15}=0.02$ & $F_{1,14}=0.05$ & $F_{1,17}=0.45$ & - \\
\hline$\Delta$ Anal plate hue & $F_{1,15}=0.50$ & $F_{2,16}=1 \cdot 72$ & $F_{1,16}=0.83$ & $F_{1,16}=0 \cdot 14$ & $F_{1,16}=4 \cdot 02^{\mathrm{m} . \mathrm{s}}$ & $F_{1,16}<0.01$ \\
\hline$\Delta$ Throat scales hue & $F_{1,18}=1 \cdot 41$ & $F_{2,16}=2 \cdot 33$ & $F_{1,16}=2 \cdot 81$ & $F_{1,16}=0 \cdot 19$ & $F_{1,16}=\mathbf{5 . 6 7} *$ & $F_{1,16}=0 \cdot 76$ \\
\hline$\Delta$ Ventral scales hue & $F_{1,15}=0.88$ & $F_{2,17}=1.89$ & $F_{1,16}=1 \cdot 72$ & $F_{1,16}=0 \cdot 02$ & $F_{1,16}=\mathbf{9} \cdot \mathbf{6 6}^{* *}$ & $F_{1,16}<0.01$ \\
\hline
\end{tabular}

Bold values are statistically significant.

$* P<0.05,{ }^{* *} P<0.01,{ }^{*} * P<0.001$, m.s. marginally significant $0.05<P \leq 0.06$

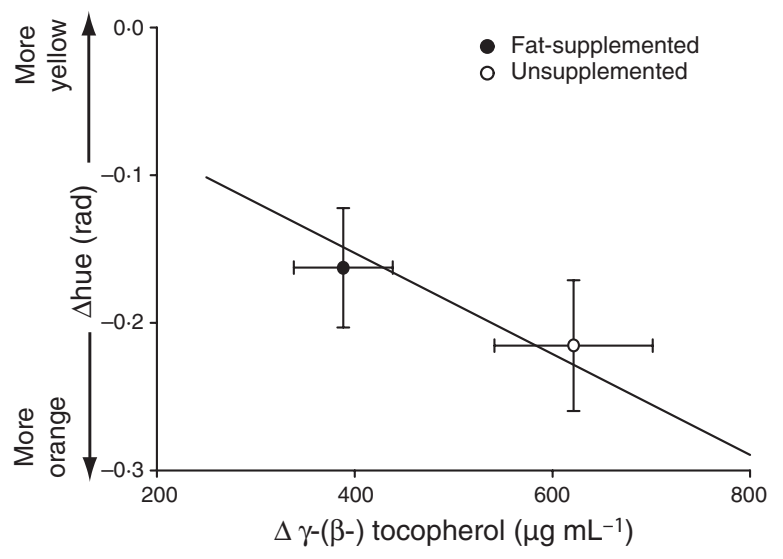

Fig. 6. Relationship between changes in ventral hue and plasma $\gamma-(\beta-)$ tocopherol concentration. Means $( \pm$ SE) for fat-supplemented and unsupplemented groups are plotted. Lines reflect model predictions for the relationship between changes in ventral hue and plasma $\gamma$-( $\beta$-) tocopherol concentration.

in mammals to species with carotenoid-based ornaments should be cautiously carried out (Hill 1999). Additional studies comparing the effect of dietary lipids in different taxa as well as in different tissues are therefore needed. Additionally, the negative effects of dietary lipids may be ultimately modulated by hormones like testosterone, which regulates lipoprotein status and which potential effects should be also addressed in future studies (McGraw, Correa \& Adkins-Regan 2006).

Fat treatment-induced tocopherol changes paralleled carotenoid changes, which is in line with the idea of shared absorption and transportation routes (Borel 2003). In plasma, we found no evidence for homoeostatic sparing or the protection hypothesis, although homoeostatic sparing may exist among other, here not analysed, tissues or antioxidant compounds (Fig. 1, paths h and g; Svensson \& Wong 2011). Carotenoid supplementation did not induce changes in plasma tocopherol concentration, suggesting that carotenoids did not substitute tocopherols as antioxidants or that tocopherols were not consumed by toxic workings of carotenoid oxidation (Palozza 1998). As suggested for carotenoids, negative interactions between lipids and tocopherols during absorption, excretion or transport are more likely to explain the negative relationship between lipid ingestion and $\gamma-(\beta-)$ tocopherol plasma concentration.

As previously observed in common lizards, carotenoid supplementation increased lutein plasma concentration while supplementation with no carotenoids decreased lutein plasma concentration (Fitze et al. 2009). Our study is therefore in line with studies on birds and fish showing that circulating carotenoid levels reflect the amount of dietary carotenoids (Fig. 1, path a; Hill et al. 1994; Grether, Hudon \& Millie 1999; Hill, Caron \& Montgomerie 2002; Clotfelter, Ardia \& McGraw 2007). Despite experimental zeaxanthin supplementation, no direct supplementation effect on plasma zeaxanthin concentration was found. Similarly, dietary lipids did also not affect plasma zeaxanthin concentration while significantly affected lutein concentration. These findings suggest that plasma zeaxanthin levels may be less flexible than plasma lutein levels. In line with these findings, the path analysis suggested that carotenoid supplementation may have negatively affected zeaxanthin plasma concentration, suggesting that lutein may be favoured over zeaxanthin in potential competitive interactions during absorption or transport (Erdman, Bierer \& Gugger 1993).

Although decreased carotenoid availability directly explains colour fading in many species showing carotenoidbased ornaments (e.g. Tschirren, Fitze \& Richner 2003), it was not responsible for the colour changes mediated here by lipid intake. The determination of carotenoid-based ornaments has been suggested to be conserved in different vertebrates groups, like birds, fish and reptiles (Peters 2007). However, our study shows that manipulation of carotenoid availability does not affect the expression of carotenoid-based ornaments, which is in sharp contrast to findings in birds and fish (Grether, Hudon \& Endler 2001; McGraw et al. 2002, 2004). This result is congruent to previous experimental studies conducted in the common lizard (Fitze et al. 2009) and 
with studies on other lizard species, where carotenoid administration did not also affect coloration (Olsson et al. 2008; Steffen, Hill \& Guyer 2010). Therefore, to date, there is no evidence that carotenoid availability limits the expression of carotenoid-based coloration in lizards (Fig. 1, path b) and, hence, the hypothesis that coloration reflects individual differences in carotenoid ingestion or in carotenoid allocation may be not supported in lizards. To fully test this hypothesis in lizards, it is still necessary to address the importance of carotenoid availability during maturation and, hence, when most lizard species develop bright colorations for the first time.

Enhanced lipid intake could have directly affected coloration through increasing the amount of lipids deposited in the epidermis (Lillywhite 2006) and/or the flexibility of the chromatophore cell membranes (Geiser 1991). However, a direct effect of lipid intake on coloration was not supported by the path analysis. The path analysis indeed showed that the negative effect of fat treatment on ventral coloration was related with the change observed in plasma $\gamma-(\beta-)$ tocopherol concentration, suggesting that lipid intake negatively affected tocopherol concentrations and thereby led to less orange and, hence, less sexually attractive coloration (Fitze et al. 2009). Our findings are in line with previous findings in the common lizard. Cote et al. (2010) showed that common lizards with less orange colorations had higher concentrations of lipid peroxidation. Increased lipid peroxidation usually diminishes circulating concentrations of tocopherols (Ibrahim et al. 1997), given that tocopherols specifically protect lipids from free radical attack (Rock, Jacob \& Bowen 1996). Consequently, in our study and Cote et al. (2010), tocopherol availability may explain the observed results. Our findings also resemble those found in other lizard species. For instance, a relationship between tocopherol concentrations and coloration was observed in male Lacerta lepida (ocellated lizard; Martín \& López 2010), and between antioxidant capacity and coloration in Ctenophorus pictus (Australian painted dragon lizard) whose carotenoid-based coloration also did not depend on dietary carotenoids (Olsson et al. 2008).

In birds and fish, dietary supplementation with tocopherols or other antioxidants enhanced carotenoid-based ornaments (Bertrand, Faivre \& Sorci 2006; Pike et al. 2007; Pérez, Lores $\&$ Velando 2008). These findings were explained by a positive effect of antioxidants on carotenoid availability, either by protecting carotenoids from oxidation or by liberating carotenoids from antioxidant functions (Svensson \& Wong 2011). In contrast, the here-observed effects on $\gamma$ - $(\beta-)$ tocopherol concentrations were not mediated by changes in carotenoid availability, indicating that a different pathway may link tocopherol concentrations with coloration. One explanation is that tocopherols may protect ornamental carotenoids directly in the integument, preventing carotenoid bleaching and colour fading (Hartley \& Kennedy 2004). Alternatively, tocopherols may be related with coloration through other integumentary colour components. The integument of the common lizards, and of reptiles in general, consists of several structural and pigment components that may also determine coloration, like melanins and iridophores (Bagnara, Taylor \& Hadley 1968; Grether, Kolluru \& Nersissian 2004). The synthesis of melanin and purine crystals of iridophores depends on oxidative stress (Glantzounis et al. 2005; Galvan \& Alonso-Alvarez 2008) and their reflective properties may therefore depend on antioxidants such as tocopherols.

Mate choice based on antioxidant-related ornaments may increase female reproductive success because antioxidant concentrations are important determinants of male fertility and survival (Catoni, Peters \& Martin Schaefer 2008; Monaghan, Metcalfe \& Torres 2009). In several lizard species, including the common lizard, males secrete tocopherol through femoral pores (Gabirot et al. 2008), which have been shown to affect female mate choice in European green lizards (Kopena et al. 2011). Females assess tocopherol content of femoral pore secretions and select males with higher tocopherol concentrations (Kopena et al. 2011). Females may benefit from this selection because males with higher tocopherol concentrations are likely to be in better condition and defend better territories, which may ultimately improve female fitness (Kopena et al. 2011). Tocopherol availability may therefore influence the expression of different signals in different sensory modalities (visual and olfactory), suggesting that it may play a predominant role in intraspecific communication and mate choice in lizards (Candolin 2003).

In conclusion, we demonstrated that supplementation with dietary lipids negatively affected plasma carotenoid and tocopherol concentrations as well as reduced the expression of the ornamental coloration of male common lizards. Despite carotenoid supplementation significantly enhancing plasma lutein concentration, it had no effect on coloration and it did not offset the negative colour effects of dietary lipids. Our study suggests that dietary lipids affected coloration through their effect on tocopherols and not through their effect on carotenoid plasma concentrations. This is a fundamental difference and suggests that ornamental coloration may provide a much more general criteria about individual health than previously thought. Our study is congruent with research on other lizard species, suggesting that colour determination in lizards may importantly differ from birds and fish, where carotenoid availability governs colour expression. Mate choice based on traits reflecting tocopherol availability may directly select for the evolution of food-selection strategies that maximize dietary intake of tocopherols to enhance antioxidant functions and improve ornamental traits (Catoni, Peters \& Martin Schaefer 2008). Given that lipids are a major, essential nutrient, a conflict between carotenoid and tocopherol uptake and lipid intake may arise depending on the degree of covariation among these compounds in natural diets. If lipid access is independent of carotenoid and/or tocopherol access, as suggested by different studies (Barker, Fitzpatrick \& Dierenfeld 1998; Finke 2002; Girling \& Raiti 2004), competitive effects among nutrients could reinforce signal honesty, given that only animals in excellent condition may afford avoiding the ingestion of fat-enriched and, hence, highly energetic food to maximize carotenoid and tocopherol intake. 


\section{Acknowledgements}

We thank Virginia Gonzalez-Jimena, Elisa Pérez and Jesús Ortega for field and laboratory assistance and Belén Pérez, Carmen Herrero and Inmaculada Blanco for conducting the HPLC analyses. The comments of two anonymous reviewers greatly improve the manuscript. We thank Hoffman-La Roche (Basel, Switzerland) for providing carotenoids and control beadlets. The capture and handling of lizards was conducted under the licenses provided by the Gobierno de Navarra. L.M.S-J. was supported by a PhD. grant (I3P 060501) from the Consejo Superior de Investigaciones Científicas (CSIC) and co-financed by the European Social Fund, and P.S.F. by funds from the Spanish Ministry of Education and Science (Programa Ramón y Cajal). Funds were provided by the Spanish Ministry of Education and Science (CGL2005-01187, CGL2008-01522) and the Swiss National Science Foundation (PPOOP3_128375).

\section{References}

Avery, R.A. (1966) Food and feeding habits of the common lizard (Lacerta vivipara) in the west of England. Journal of Zoology, 149, 115-121.

Avery, R.A. (1970) Utilization of caudal fat by hibernating common lizards, Lacerta vivipara. Comparative Biochemistry and Physiology, 37, 119-121.

Avery, R.A. (1971) Estimates of food consumption by the lizard Lacerta vivipara Jacquin. Journal of Animal Ecology, 40, 351-365.

Bagnara, J.T., Taylor, J.D. \& Hadley, M.E. (1968) The dermal chromatophore unit. Journal of Cell Biology, 38, 67-79.

Ballinger, R.E., Holy, L., Rowe, J.W., Karst, F., Ogg, C.L. \& Stanley-Samuelson, D.W. (1992) Seasonal changes in lipid composition during the reproductive cycle of the red-chinned lizard, Sceloporus undulatus erythrocheilus. Comparative Biochemistry and Physiology Part B: Comparative Biochemistry, 103, 527-531.

Barker, D., Fitzpatrick, M.P. \& Dierenfeld, E.S. (1998) Nutrient composition of selected whole invertebrates. Zoo Biology, 17, 123-134.

Barlow, J.S.(1963) Fatty acid characteristics of someinsect taxa. Nature, 197, 311.

Bashan, M. (2005) Changes in composition of phospholipid and triacylglycerol fatty acids prepared from prediapausing and diapausing individuals of $\mathrm{Dol}$ ycoris baccarum and Piezodorus lituratus (heteroptera: pentatomidae). Annals of the Entomological Society of America, 98, 575-579.

Bauwens, D., Nuijten, K., Van Wezel, H. \& Verheyen, R.F. (1987) Sex recognition by males of the lizard Lacerta vivipara: an introductory study. Amphibia-Reptilia, 8, 49-57.

Bendich, A. (1989) Carotenoids and the immune response. The Journal of Nutrition, 119, 112-115.

Bertrand, S., Faivre, B. \& Sorci, G. (2006) Do carotenoid-based sexual traits signal the availability of non-pigmentary antioxidants? Journal of Experimental Biology, 209, 44144419.

Bleu, J., Le Galliard, J.-F., Meylan, S., Massot, M. \& Fitze, P.S. (2011) Mating does not influence reproductive investment, in a viviparous lizard. Journal of Experimental Zoology Part A: Ecological Genetics and Physiology, 315A, $458-464$.

Borel, P. (2003) Factors affecting intestinal absorption of highly lipophilic food microconstituents (fat-soluble vitamins, carotenoids and phytosterols). Clinical Chemistry and Laboratory Medicine, 41, 979-994.

Borel, P., Tyssandier, V., Mekki, N., Grolier, P., Rochette, Y., AlexandreGouabau, M.C., Lairon, D. \& Azais-Braesco, V. (1998) Chylomicron betacarotene and retinyl palmitate responses are dramatically diminished when men ingest beta-carotene with medium-chain rather than long-chain triglycerides. The Journal of Nutrition, 128, 1361-1367.

Brown, M.J., Ferruzzi, M.G., Nguyen, M.L., Cooper, D.A., Eldridge, A.L., Schwartz, S.J. \& White, W.S. (2004) Carotenoid bioavailability is higher from salads ingested with full-fat than with fat-reduced salad dressings as measured with electrochemical detection. The American Journal of Clinical Nutrition, 80, 396-403.

Buckner, J.S., Kemp, W.P. \& Bosch, J. (2004) Characterization of triacylglycerols from overwintering prepupae of the alfalfa pollinator Megachile rotundata (hymenoptera: megachilidae). Archives of Insect Biochemistry and Physiology, 57, 1-14.

Candolin, U. (2003) The use of multiple cues in mate choice. Biological Reviews, 78, 575-595.

Cartland-Shaw, L.K., Cree, A., Skeaff, C.M. \& Grimmond, N.M. (1998) Differences in dietary and plasma fatty acids between wild and captive populations of a rare reptile, the tuatara (Sphenodon punctatus). Journal of Comparative Physiology Part B: Biochemical, Systemic, and Environmental Physiology, 168, 569-580.
Catoni, C., Peters, A. \& Martin Schaefer, H. (2008) Life history trade-offs are influenced by the diversity, availability and interactions of dietary antioxidants. Animal Behaviour, 76, 1107-1119.

Chew, B.P. \& Park, J.S. (2004) Carotenoid action on the immune response. The Journal of Nutrition, 134, 257S-261S

Clotfelter, E.D., Ardia, D.R. \& McGraw, K.J. (2007) Red fish, blue fish: tradeoffs between pigmentation and immunity in Betta splendens. Behavioral Ecology, 18, 1139-1145.

Cote, J., Meylan, S., Clobert, J. \& Voituron, Y. (2010) Carotenoid-based coloration, oxidative stress and corticosterone in common lizards. Journal of Experimental Biology, 213, 2116-2124.

Dimitrov, N.V., Meyer, C., Ullrey, D.E., Chenoweth, W., Michelakis, A., Malone, W., Boone, C. \& Fink, G. (1988) Bioavailability of beta-carotene in humans. The American Journal of Clinical Nutrition, 48, 298-304.

Endler, J.A. (1990) On the measurement and classification of color in studies of animal color patterns. Biological Journal of the Linnean Society, 41, 315-352.

Erdman, J.W., Bierer, T.L. \& Gugger, E.T. (1993) Absorption and transport of carotenoids. Annals of the New York Academy of Sciences, 691, 76-85.

Fast, P.G. (1966) A comparative study of phospholipids and fatty acids of some insects. Lipids, 1, 209-215.

Finke, M.D. (2002) Complete nutrient composition of commercially raised invertebrates used as food for insectivores. Zoo Biology, 21, 269-285.

Fitze, P.S. \& Le Galliard, J.-F. (2008) Operational sex ratio, sexual conflict and the intensity of sexual selection. Ecology Letters, 11, 432-439.

Fitze, P., Tschirren, B., Gasparini, J. \& Richner, H. (2007) Carotenoid-based plumage colors and immune function: is there a trade-off for rare carotenoids? The American Naturalist, 169, S137-S144.

Fitze, P.S., Cote, J., San-Jose, L.M., Meylan, S., Isaksson, C., Andersson, S., Rossi, J.-M. \& Clobert, J. (2009) Carotenoid-based colours reflect the stress response in the common lizard. PLoS One, 4, e5111.

Gabirot, M., López, P., Martín, J., De Fraipont, M., Heulin, B., Sinervo, B. \& Clobert, J. (2008) Chemical composition of femoral secretions of oviparous and viviparous types of male common lizards Lacerta vivipara. Biochemical Systematics and Ecology, 36, 539-544.

Galvan, I. \& Alonso-Alvarez, C. (2008) An intracellular antioxidant determines the expression of a melanin-based signal in a bird. PLoS One, 3, e3335.

Geiser, F. (1991) The effect of unsaturated and saturated dietary lipids on the pattern of daily torpor and the fatty acid composition of tissues and membranes of the deer mouse Peromyscus maniculatus. Journal of Comparative Physiology Part B: Biochemical, Systemic, and Environmental Physiology, 161, 590-597.

Girling, S.J. \& Raiti, P. (2004) BSAVA Manual of Reptiles. British Small Animal Veterinary Association, Dorset.

Glantzounis, G.K., Tsimoyiannis, E.C., Kappas, A.M. \& Galaris, D.A. (2005) Uric acid and oxidative stress. Current Pharmaceutical Design, 11, 41454151 .

Goodwin, T.W. (1986) Metabolism, nutrition, and function of carotenoids. Annual Review of Nutrition, 6, 273-297.

Grether, G.F., Hudon, J. \& Endler, J.A. (2001) Carotenoid scarcity, synthetic pteridine pigments and the evolution of sexual coloration in guppies (Poecilia reticulata). Proceedings of the Royal Society B: Biological Sciences, 268, $1245-1253$.

Grether, G.F., Hudon, J. \& Millie, D.F. (1999) Carotenoid limitation of sexual coloration along an environmental gradient in guppies. Proceedings of the Royal Society B: Biological Sciences, 266, 1317-1322.

Grether, G., Kolluru, G. \& Nersissian, K. (2004) Individual colour patches as multicomponent signals. Biological Reviews, 79, 583-610.

Hartley, R.C. \& Kennedy, M.W. (2004) Are carotenoids a red herring in sexual display? Trends in Ecology and Evolution, 19, 353-354.

Heulin, B. (1986) Estival diet and use of trophic resources in 3 populations of Lacerta vivipara. Acta Oecologica: Oecologia Generalis, 7, 135-150.

Hill, G.E. (1990) Female house finches prefer colourful males: sexual selection for a condition-dependent trait. Animal Behaviour, 40, 563-572.

Hill, G.E. (1999) Is there an immunological cost to carotenoid-based ornamental coloration? The American Naturalist, 154, 589-595.

Hill, G.E. (2000) Energetic constraints on expression of carotenoid-based plumage coloration. Journal of Avian Biology, 31, 559-566.

Hill, G.E., Caron, Y.I. \& Montgomerie, R. (2002) Dietary carotenoids predict plumage coloration in wild house finches. Proceedings of the Royal Society B: Biological Sciences, 269, 1119-1124.

Hill, G.E., Montgomerie, R., Inouye, C.Y. \& Dale, J. (1994) Influence of dietary carotenoids on plasma and plumage colour in the house finch: intraand intersexual variation. Functional Ecology, 8, 343-350.

Hochberg, Y. (1988) A sharper bonferroni procedure for multiple tests of significance. Biometrika, 75, 800-802. 
van het Hof, K.H., West, C.E., Weststrate, J.A. \& Hautvast, J.G.A.J. (2000) Dietary factors that affect the bioavailability of carotenoids. The Journal of Nutrition, 130, 503-506.

Ibrahim, W., Lee, U.-S., Yeh, C.-C., Szabo, J., Bruckner, G. \& Chow, C.K (1997) Oxidative stress and antioxidant status in mouse liver: effects of dietary lipid, vitamin E and iron. The Journal of Nutrition, 127, 1401-1406.

Khani, A., Moharramipour, S., Barzegar, M. \& Naderi-Manesh, H. (2007) Comparison of fatty acid composition in total lipid of diapause and non-diapause larvae of Cydia pomonella (lepidoptera: tortricidae). Insect Science, 14, 125-131.

Kopena, R., Martín, J., López, P. \& Herczeg, G. (2011) Vitamin E supplementation increases the attractiveness of males' scent for female European green lizards. PLoS One, 6, e19410.

Krinsky, N.I. (1989) Antioxidant functions of carotenoids. Free Radical Biology and Medicine, 7, 617-635.

Lessells, C.M. \& Boag, A.M. (1987) Unrepeatable repeatabilities - a common mistake. The Auk, 104, 116-121.

Lillywhite, H.B. (2006) Water relations of tetrapod integument. Journal of Experimental Biology, 209, 202-226.

Littell, R.C., Henry, P.R. \& Ammerman, C.B. (1998) Statistical analysis of repeated measures data using SAS procedures. Journal of Animal Science, 76, 1216-1231.

Lozano, G. (1994) Carotenoids, parasites, and sexual selection. Oikos, 70, 309 311.

Martín, J. \& López, P. (2010) Multimodal sexual signals in male ocellated lizards Lacerta lepida: vitamin E in scent and green coloration may signal male quality in different sensory channels. Naturwissenschaften, 97, 545-553.

McGraw, K., Correa, S. \& Adkins-Regan, E. (2006) Testosterone upregulates lipoprotein status to control sexual attractiveness in a colorful songbird. Behavioral Ecology and Sociobiology, 60, 117-122.

McGraw, K.J. \& Parker, R.S. (2006) A novel lipoprotein-mediated mechanism controlling sexual attractiveness in a colorful songbird. Physiology and Behavior, 87, 103-108.

McGraw, K.J., Hill, G.E., Stradi, R. \& Parker, R.S. (2002) The effect of dietary carotenoid access on sexual dichromatism and plumage pigment composition in the American goldfinch. Comparative Biochemistry and Physiology Part B: Biochemistry and Molecular Biology, 131, 261-269.

McGraw, K.J., Hill, G.E., Navara, K.J. \& Parker, R.S. (2004) Differential accumulation and pigmenting ability of dietary carotenoids in colorful finches. Physiological and Biochemical Zoology, 77, 484- 491.

Michaud, M.R. \& Denlinger, D.L. (2006) Oleic acid is elevated in cell membranes during rapid cold-hardening and pupal diapause in the flesh fly, Sarcophaga crassipalpis. Journal of Insect Physiology, 52, 1073-1082.

Monaghan, P., Metcalfe, N.B. \& Torres, R. (2009) Oxidative stress as a mediator of life history trade-offs: mechanisms, measurements and interpretation. Ecology Letters, 12, 75-92.

Nakagawa, S. \& Cuthill, I.C. (2007) Effect size, confidence interval and statistical significance: a practical guide for biologists. Biological Reviews, 82, 591.

Neter, J., Kutner, M.H., Nachtsheim, C.J. \& Wasserman, W. (1996) Applied Linear Statistical Models. Irwin, Illinois.

Olmedilla, B., Granado, F., Gil-Martinez, E., Blanco, I. \& Rojas-Hidalgo, E. (1997) Reference values of retinol, $\alpha$-tocopherol and main carotenoids in serum of control and insulin-dependent diabetic spanish subjects. Clinical Chemistry, 43, 1066-1071.

Olson, V.A. \& Owens, I.P.F. (1998) Costly sexual signals: are carotenoids rare, risky or required? Trends in Ecology and Evolution, 13, 510-514.

Olsson, M., Wilson, M., Isaksson, C., Uller, T. \& Mott, B. (2008) Carotenoid intake does not mediate a relationship between reactive oxygen species and bright colouration: experimental test in a lizard. Journal of Experimental Biology, 211, 1257-1261.

Palozza, P. (1998) Prooxidant actions of carotenoids in biologic systems. Nutrition Reviews, 56, 257-265.
Parker, R.S. (1996) Absorption, metabolism, and transport of carotenoids. The FASEB Journal, 10, 542-551.

Pérez, C., Lores, M. \& Velando, A. (2008) Availability of nonpigmentary antioxidant affects red coloration in gulls. Behavioral Ecology, 19, 967-973.

Pérez-Rodríguez, L. (2009) Carotenoids in evolutionary ecology: re-evaluating the antioxidant role. Bioessays, 31, 1116-1126.

Peters, A. (2007) Testosterone and carotenoids: an integrated view of trade-offs between immunity and sexual signalling. Bioessays, 29, 427-430.

Pike, T.W., Blount, J.D., Lindström, J. \& Metcalfe, N.B. (2007) Availability of non-carotenoid antioxidants affects the expression of a carotenoid-based sexual ornament. Biology Letters, 3, 353-356.

Ribaya-Mercado, J.D. (2002) Influence of dietary fat on $\beta$-carotene absorption and bioconversion into vitamin A. Nutrition Reviews, 60, 104-110.

Rock, C.L., Jacob, R.A. \& Bowen, P.E. (1996) Update on the biological characteristics of the antioxidant micronutrients: vitamin C, vitamin E, and the carotenoids. Journal of the American Dietetic Association, 96, 693-702.

Roig, J.M., Carretero, M.A. \& Llorente, G.A. (2000) Reproductive cycle in a Pyrenean oviparous population of the common lizard (Zootoca vivipara). Netherlands Journal of Zoology, 50, 15-27.

San-Jose, L.M., Granado-Lorencio, F. \& Fitze, P.S. (2012) Vitamin E, vitamin A, and carotenoids in male common lizard tissues. Herpetologica, 68, 88-99.

von Schantz, T., Bensch, S., Grahn, M., Hasselquist, D. \& Wittzell, H. (1999) Good genes, oxidative stress and condition-dependent sexual signals. Proceedings of the Royal Society B: Biological Sciences, 266, 1-12.

Schneider, M. \& Dorn, A. (1994) Lipid storage and mobilization by flight in relation to phase and age of Schistocerca gregaria females. Insect Biochemistry and Molecular Biology, 24, 883-889.

Silva, K.D.R.R., Kelly, C.N.M., Jones, A.E., Smith, R.D., Wootton, S.A., Miller, G.J. \& Williams, C.M. (2003) Chylomicron particle size and number, factor VII activation and dietary monounsaturated fatty acids. Atherosclerosis, 166, 73-84.

Sindaco, R. \& Jeremcenko, V.K. (2008) The Reptiles of the Western Paleartic. Edizioni Belvedere, Latina.

Speake, B.K., Herbert, J.F. \& Thompson, M.B. (2004) Comparison of the fatty-acid compositions of prey items and yolks of Australian insectivorous scincid lizards. Journal of Comparative Physiology Part B: Biochemical, Systemic, and Environmental Physiology, 174, 393-397.

Steffen, J.E., Hill, G.E. \& Guyer, C. (2010) Carotenoid access, nutritional stress, and the dewlap color of male brown anoles. Copeia, 2010, 239-246.

Surai, P.F. (2002) Natural Antioxidants in Avian Nutrion and Reproduction. Nottingham University Press, Nottingham.

Svensson, P.A. \& Wong, B.B.M. (2011) Carotenoid-based signals in behavioural ecology: a review. Behaviour, 148, 131-189.

Thompson, M.B., Speake, B.K., Russell, K.J. \& Mccartney, R.J. (2001) Nutrient uptake by embryos of the Australian viviparous lizard Eulamprus tympanum. Physiological and Biochemical Zoology, 74, 560-567.

Tschirren, B., Fitze, P.S. \& Richner, H. (2003) Proximate mechanisms of variation in the carotenoid-based plumage coloration of nestling great tits (Parus major L.). Journal of Evolutionary Biology, 16, 91-100.

Unlu, N.Z., Bohn, T., Clinton, S.K. \& Schwartz, S.J. (2005) Carotenoid absorption from salad and salsa by humans is enhanced by the addition of avocado or avocado oil. The Journal of Nutrition, 135, 431-436.

Wolfinger, R.D. (1996) Heterogeneous variance: covariance structures for repeated measures. Journal of Agricultural, Biological, and Environmental Statistics, 1, 205-230.

Yonekura, L. \& Nagao, A. (2007) Intestinal absorption of dietary carotenoids. Molecular Nutrition and Food Research, 51, 107-115.

Received 15 August 2011; accepted 23 January 2012

Handling Editor: Peter Niewiarowski 